\title{
NMR and LC-MS assessment of compound variability of common bean (Phaseolus vulgaris) stored under controlled atmosphere
} \author{
Edy S. de Brito ${ }^{c}$ \\ ${ }^{a}$ Universidade Estadual do Oeste do Paraná, 85819-110, Cascavel, PR, Brazil \\ ${ }^{\mathrm{b}}$ Department of Food Engineering, Universidade Federal do Ceará, 60440-900, Fortaleza, CE, Brazil \\ ${ }^{\mathrm{c}}$ Embrapa Agroindústria Tropical, Rua Dra Sara Mesquita, 2270, Pici, 60020-181, Fortaleza, CE, Brazil \\ ${ }^{\mathrm{d}}$ Embrapa Arroz e Feijão, 75375-000, Santo Antônio de Goiás, GO, Brazil
}

Silvia Renata M. Coelho ${ }^{\mathrm{a}}$, Elenilson G. Alves Filho ${ }^{\mathrm{b}, *}$, Lorena Mara A. Silva ${ }^{\mathrm{c}}$, Tabata Z. Bischoff ${ }^{\mathrm{a}}$, Paulo R.V. Ribeiro ${ }^{c}$, Guilherme Julião Zocolo ${ }^{c}$, Kirley M. Canuto ${ }^{c}$, Priscila Z. Bassinello ${ }^{\mathrm{d}}$,

\section{A R T I C L E IN F O}

\section{Keywords:}

Phaseolus vulgaris

Browning

Primary metabolites

Secondary metabolites

Chemometrics

\begin{abstract}
A B S T R A C T
As the chemical profiling of common beans (Phaseolus vulgaris) modify according to storage conditions, the aim of this study was to analyze the physicochemical parameters and composition variability of the cotyledon by NMR, and coat by LC-MS, all submitted to different storage atmosphere of $\mathrm{O}_{2}, \mathrm{CO}_{2}$, and humidity. Through NMR, chemometrics along with metabolite pathway analysis it is observed the overexpression of the saccharides sucrose (from $2.30 \pm 0.32$ to $2.71 \pm 0.14 \mathrm{~g} / 100 \mathrm{~g}$ ), raffinose (from $0.86 \pm 0.04$ to $1.02 \pm 0.07 \mathrm{~g} / 100 \mathrm{~g}$ ), and stachyose (from $3.37 \pm 0.12$ to $4.13 \pm 0.28 \mathrm{~g} / 100 \mathrm{~g}$ ) in stored beans (regardless atmosphere conditions), indicating changing on galactose, and starch and sucrose pathways that are intrinsically linked to germination and sprouting processes. Those mechanisms seem to be partially activated after 6 months since amino acids or lipid metabolism were not affected. Therefore, storage conditions induce the role in regulating the germination and sprouting processes but do not affect the germination capability of the seeds (data not shown). The beans stored in low humidity showed less luminosity and chroma values, and relative reduction of proanthocyanidin B-type dimer, epi-catechin, and kaempferol, which indicate darkening when submitted to high humidity with controlled atmosphere.
\end{abstract}

\section{Introduction}

The chemical profile of common beans (Phaseolus vulgaris) can change according to storage conditions (Prolla et al., 2010). Storage under adverse conditions as high temperature and humidity induces the hard-to-cook (HTC), a textural defect that affects its quality (K. Liu, McWatters, \& Phillips, 1992). The impermeability of the bean coat occurs due to oxidation of tannins and formation of protein-tannin complexes (Pirhayati, Soltanizadeh, \& Kadivar, 2011). Furthermore, the environment during the storage may cause changes in seed metabolism and influence the physiological quality of seeds (Delouche \& Baskin, 2016). Therefore, the use of reduced oxygen levels and increase of gases, such as carbon dioxide $\left(\mathrm{CO}_{2}\right)$ and nitrogen to control storage pests, can lead to inhibition of biochemical processes as sucrose, amino acids, and lipids biosynthesis (Geigenberger, 2003).

Modified atmosphere technologies are well-known methods and are alternative for preserving beans quality by reducing chemical changes
(Vanier, Rupollo, Paraginski, de Oliveira, \& Elias, 2014) and extending shelf life due to the decrease of microorganisms incidence (Freitas, Faroni, \& Sousa, 2016). In normal atmosphere conditions, the concentrations of nitrogen $\left(\mathrm{N}_{2}\right)$, oxygen $\left(\mathrm{O}_{2}\right)$, and carbon dioxide $\left(\mathrm{CO}_{2}\right)$ are $78 \%, 21 \%$, and $0.04 \%$ respectively, along with small percentages of other gases. In order to increase the shelf life of products stored under controlled atmospheres, it is necessary to reduce $\mathrm{O}_{2}$ concentrations to $1-3 \%$ while increase levels of $\mathrm{CO}_{2}$ to $2-20 \%$ (de Souza Aguiar et al., 2015).

Therefore, the aim of this study was evaluate the composition variability of common bean under different storage conditions using the quantitative Nuclear Magnetic Resonance ( $q$ NMR), and Ultra-High Performance Liquid Chromatography coupled to High Resolution Mass Spectrometry (UPLC-HRMS) to evaluate the chemical changes according to different controlled atmosphere conditions as storage period and levels of $\mathrm{O}_{2}, \mathrm{CO}_{2}$, and humidity.

\footnotetext{
* Corresponding author.

E-mail address: elenilson.godoy@yahoo.com.br (E.G. Alves Filho).
} 
Table 1

Storage conditions of the common beans ( $P$. vulgaris).

\begin{tabular}{|c|c|c|c|c|}
\hline Experiment & $\% \mathrm{O}_{2}(\mathrm{kPa})$ & $\% \mathrm{CO}_{2}(\mathrm{kPa})$ & Storage period & Relative humidity \\
\hline T1(HCLH) & 1.5 & 9 & 6 months & $40 \%$ \\
\hline T2(LCLH) & 21 & 0.04 & 6 months & $40 \%$ \\
\hline T3(HCHH) & 1.5 & 9 & 6 months & $70 \%$ \\
\hline T4(LCHH) & 21 & 0.04 & 6 months & $70 \%$ \\
\hline T5(HCLH.sl) & 1.5 & 9 & 6 months +7 days sl & $40 \%$ \\
\hline T6(LCLH.sl) & 21 & 0.04 & 6 months +7 days sl & $40 \%$ \\
\hline T7(HCHH.sl) & 1.5 & 9 & 6 months +7 days sl & $70 \%$ \\
\hline T8(LCHH.sl) & 21 & 0.04 & 6 months +7 days sl & $70 \%$ \\
\hline
\end{tabular}

Legend: $\mathrm{LCLH}$ - low $\mathrm{CO}_{2}$ level, low humidity; LCHH - low $\mathrm{CO}_{2}$ level, high humidity; $\mathrm{HCLH}$ - high $\mathrm{CO}_{2}$ level; $\mathrm{HCHH}$ - high $\mathrm{CO}_{2}$ level, high humidity; sl - storage in normal atmosphere at $25^{\circ} \mathrm{C}$.

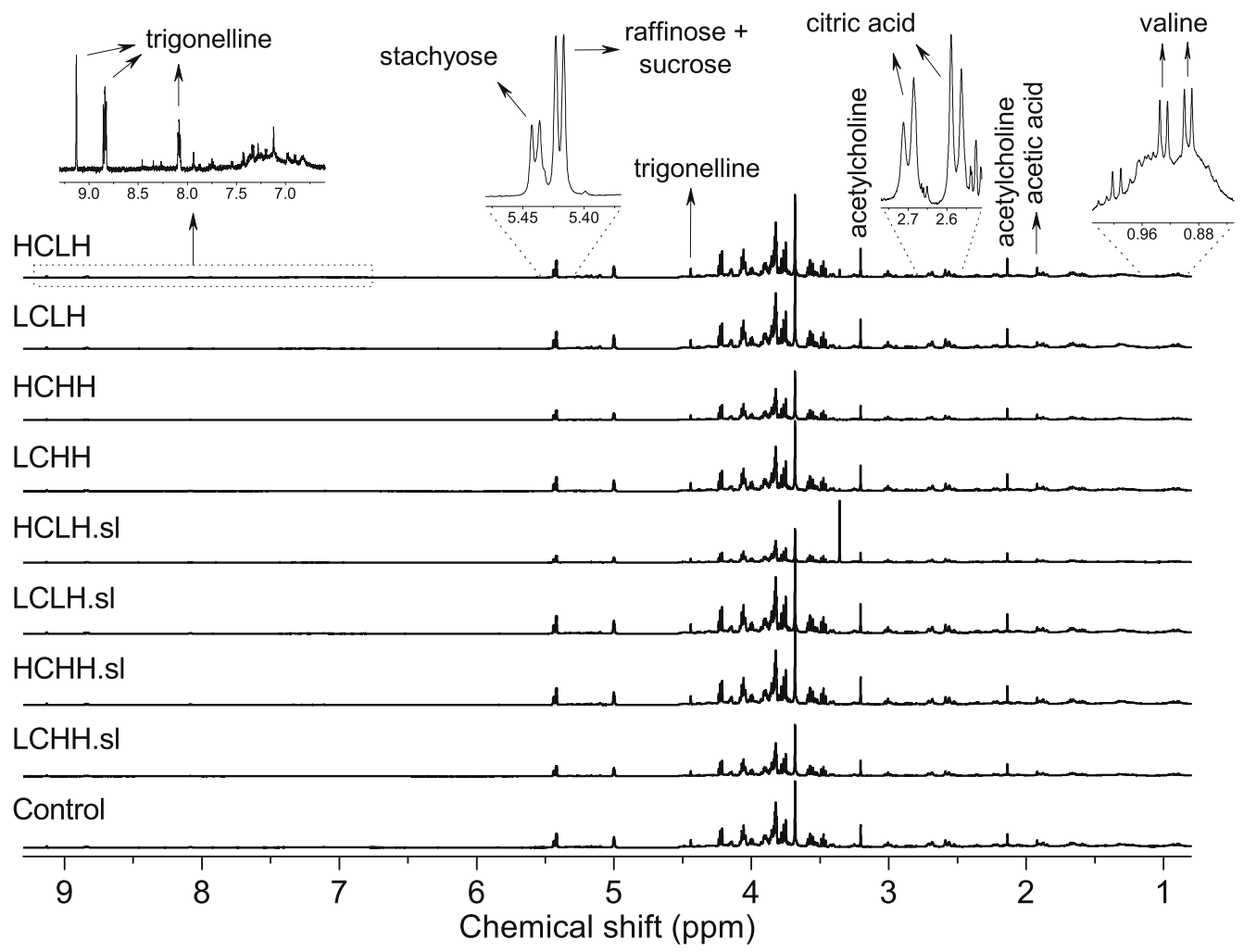

Fig. 1. Overview of the ${ }^{1} \mathrm{H}$ NMR spectra from aqueous extract of cotyledon of Phaseoulus vulgaris. Legend: $\mathrm{LCLH}-$ low $\mathrm{CO}_{2}$ level, low humidity; $\mathrm{LCHH}_{-}$low $\mathrm{CO}_{2}$ level, high humidity; $\mathrm{HCLH}$ - high $\mathrm{CO}_{2}$ level; $\mathrm{HCHH}$ - high $\mathrm{CO}_{2}$ level, high humidity; sl - storage at ambient condition.

\section{Materials and methods}

\subsection{Samples}

Phaseolus vulgaris type Pinto Bean (cv. IAC Imperador) was harvested on January 2016 in a farm located at Paraná State, Brazil - latitude $24^{\circ} 54^{\prime} 74^{\prime \prime} \mathrm{S}$, longitude $54^{\circ} 03^{\prime} 50^{\prime \prime} \mathrm{W}$. These beans were harvested, cleaned, and stored in raffia bags with moisture content of $11 \%$.

\subsection{Experimental layout}

The experimental design was completely randomized with four replications. Approximately $350 \mathrm{~g}$ of dry beans were placed in different storage conditions of $\mathrm{CO}_{2}(0.04$ and $9 \%), \mathrm{O}_{2}$ (1.5 and 21\%) and relative humidity (40 and 70\%), as described in Table 1 . In controlled atmosphere, $350 \mathrm{~g}$ were stored in raffia bags and placed in $15 \mathrm{~L}$ airtight vessels $(N=3)$. These conditions were obtained with nitrogen and carbon dioxide (White Martins Gases Industriais Ltda, Cascavel, Brazil). Both gases were mixed to obtain the oxygen $(1.5 \mathrm{KPa})$ and carbon dioxide $(9.0 \mathrm{KPa})$ levels and were monitored for six months using an electronic analyzer - Agri-Datalog ${ }^{\mathrm{TM}}$ Oxidox II Isocel (Rio Grande do Sul, Brazil). The relative humidity (40 and $60 \%)$ and temperature $\left(20^{\circ} \mathrm{C}\right.$ ) were adjusted and controlled by a dehumidifier and air conditioner, respectively. After six months a subset of samples were maintained under ambient atmosphere at $25^{\circ} \mathrm{C}$ (stored at ambient condition - sl) to evaluate the capacity of metabolic restoration. At the end of the experiments, $100 \mathrm{~g}$ of beans were frozen at $-25^{\circ} \mathrm{C}$ for $24 \mathrm{~h}$ and freeze dried (Terroni, model Enterprise II, São Carlos, Brazil). A control sample before storage was obtained as described above.

\subsection{NMR analysis}

For NMR analysis, the bean coat was manually separated from the cotyledon. The cotyledon were powdered, and approximately $30.0 \mathrm{mg}$ were soaked in a mixture of $600 \mu \mathrm{L}$ of $\mathrm{D}_{2} \mathrm{O}$ and $1 \mathrm{mM}$ of TMSP- $\mathrm{d}_{4}$ (sodium-3-trimethylsilylpropionate-2,2,3,3- $\mathrm{d}_{4}$ ). The solutions were mixed for $2 \mathrm{~min}$ at room temperature and centrifuged at $804.6 \mathrm{~g}$ for $2 \mathrm{~min}$. The supernatants were transferred to $5 \mathrm{~mm}$ NMR tubes. 


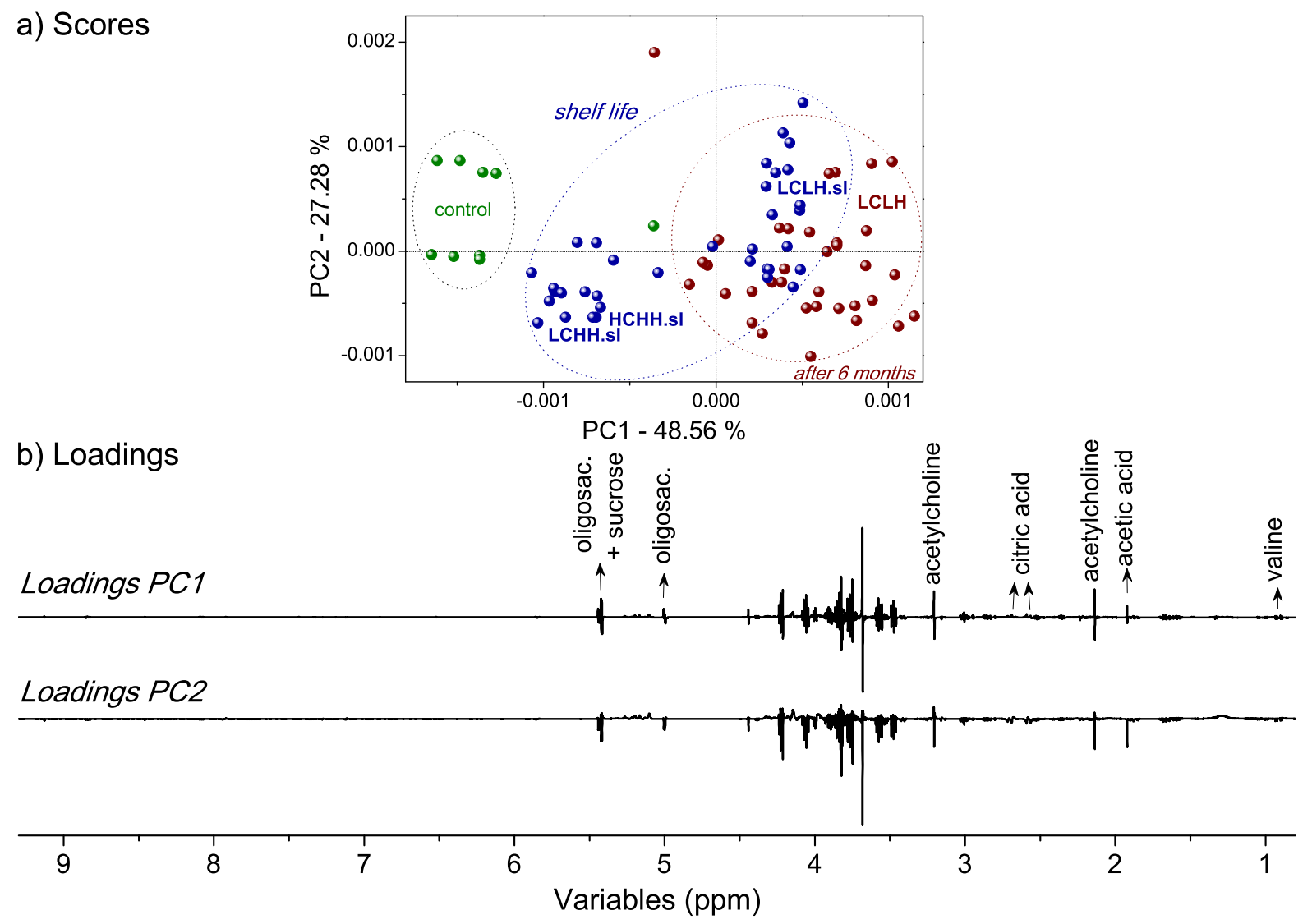

Fig. 2. PC1 $\times$ PC2 scores coordinate system for common bean stored under different conditions, with control samples (green), beans stored during 6 months (red), and beans stored during 6 months with subsequent storage at ambient condition (blue) (a); respective loadings plotted in lines form (b). Legend: LCLH - low CO level, low humidity; $\mathrm{LCHH}$ - low $\mathrm{CO}_{2}$ level, high humidity; $\mathrm{HCLH}$ - high $\mathrm{CO}_{2}$ level; $\mathrm{HCHH}$ - high $\mathrm{CO}_{2}$ level, high humidity; sl - storage at ambient condition. (For interpretation of the references to color in this figure legend, the reader is referred to the Web version of this article.)

The NMR experiments were performed on an Agilent $600-\mathrm{MHz}$ spectrometer equipped with a $5 \mathrm{~mm}\left(\mathrm{H}-\mathrm{F} /{ }^{15} \mathrm{~N}-{ }^{31} \mathrm{P}\right)$ inverse detection One Probe ${ }^{\mathrm{TM}}$ with actively shielded Z-gradient. The ${ }^{1} \mathrm{H}$ NMR spectra were acquired with 32 free induction decays (FID), $48 \mathrm{k}$ of time domain points for a spectral window of $16 \mathrm{ppm}$, under quantitative parameters at $298 \mathrm{~K}$ : acquisition time of $5.0 \mathrm{~s}$ and a recycling delay of $25.0 \mathrm{~s}$ (determined by the inversion-recovery pulse sequence). The spectra were processed by applying exponential line broadening of $0.3 \mathrm{~Hz}$, zero filling of $32 \mathrm{k}$ points, and referenced to the TMSP- $\mathrm{d}_{4}$ resonance at $\delta 0.0$. The identification of the constituents was performed through ${ }^{1} \mathrm{H}-{ }^{1} \mathrm{H}$ COSY, ${ }^{1} \mathrm{H}-{ }^{13} \mathrm{C}$ HSQC, and ${ }^{1} \mathrm{H}_{-}{ }^{13} \mathrm{C}$ HMBC experiments, supplementary open access database (http://www.hmdb.ca) and literature reports (Alves Filho, Silva, Teofilo, Larsen, \& de Brito, 2017; Choze et al., 2013; Lião et al., 2011). Complete signaling is provided in Supporting Information (SI).

\subsection{LC-MS analysis}

The bean coat samples were grinded and $200 \mathrm{mg}$ was sonicated (40 kHz, Eco-Sonic, Brazil) in $10 \mathrm{~mL}$ of acidified methanol: acetic acid (90/10, v/v) during $1 \mathrm{~h}$ at $25^{\circ} \mathrm{C}$. The supernatant was filtered on PTFE $0.2 \mu \mathrm{m}$ membranes (Whatman, Merck, Germany) and $5 \mu \mathrm{L}$ was injected into the UPLC system (Waters Co., Milford, MA, USA). The UPLC analysis was performed with Acquity UPLC BEH column $(150 \times 2.1 \mathrm{~mm}$, $1.7 \mu \mathrm{m}$; Waters) on a Waters Acquity UPLC system. The column temperature was set at $40{ }^{\circ} \mathrm{C}$. The binary gradient elution system consisted of $0.1 \%$ formic acid in water (A) and $0.1 \%$ formic acid in acetonitrile (B), with linear gradient from 2 to $95 \%$ B (0-15 min), with a flow rate of $0.4 \mathrm{~mL} \mathrm{~min}^{-1}$. The profiling was obtained by a Xevo Q-TOF mass spectrometer (Waters) with electrospray ionization (ESI) interface operating in negative ionization mode in the range of $110-1180 \mathrm{Da}$ with scan time of 0.1 . The desolvation gas was nitrogen set at $350{ }^{\circ} \mathrm{C}$ with flow rate of $500 \mathrm{~L} \mathrm{~h}^{-1}$. The capillary and cone voltages were adjusted to $2.6 \mathrm{kV}$ and $0.5 \mathrm{~V}$, respectively. The mass accuracy and reproducibility were maintained by infusing lock mass (leucine-enkephalin, $0.2 \mathrm{ng} \mathrm{\mu L}^{-1} ;[\mathrm{M}-\mathrm{H}]^{-}$ion at $\left.m / z 556.2771\right)$ and molecular formula assignments were obtained by MassLynx 4.1 software (Waters Corporation). The identification of the organic compounds was performed considering the respective $m / z$ values, fragmentation profile, and literature reports.

\subsection{Color measurement}

Color was determined using a Minolta CR-410 chromameter (Minolta, Japan) with granular-materials attachment CRA50. A white porcelain plate $(\mathrm{Y}=85.8 ; \mathrm{x}=0.3195$ and $\mathrm{y}=0.3369)$ was used for calibration, and an illuminat D65 (day light) to data collection for $\mathrm{L}^{*}$ (luminosity), $\mathrm{a}^{*}$, and $\mathrm{b} *$ values. The hue angle $\left(\mathrm{h}^{*}\right)$ and chroma $\left(\mathrm{C}^{*}\right)$ values were determined based on a previous publication (Giusti, Caprioli, Ricciutelli, Vittori, \& Sagratini, 2017).

\subsection{Statistical analysis}

\subsubsection{Multivariate statistical analysis}

The NMR and LC-MS dataset were evaluated by multivariate statistical analysis. Therefore, the ${ }^{1} \mathrm{H}$ NMR spectra and chromatograms were converted to American Standard Code for Information Interchange (ASCII) files to covariance matrices construction separately 

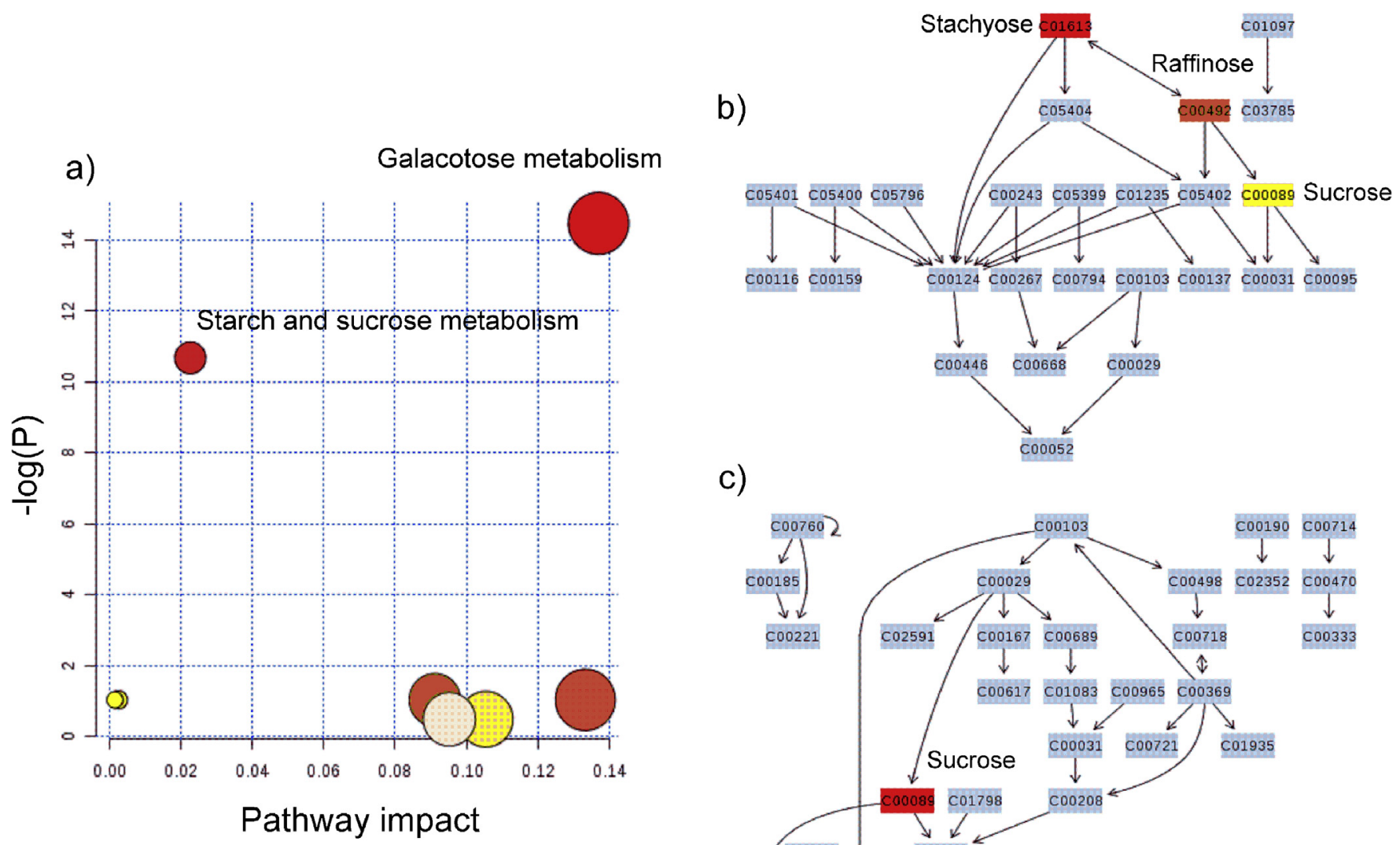

c)

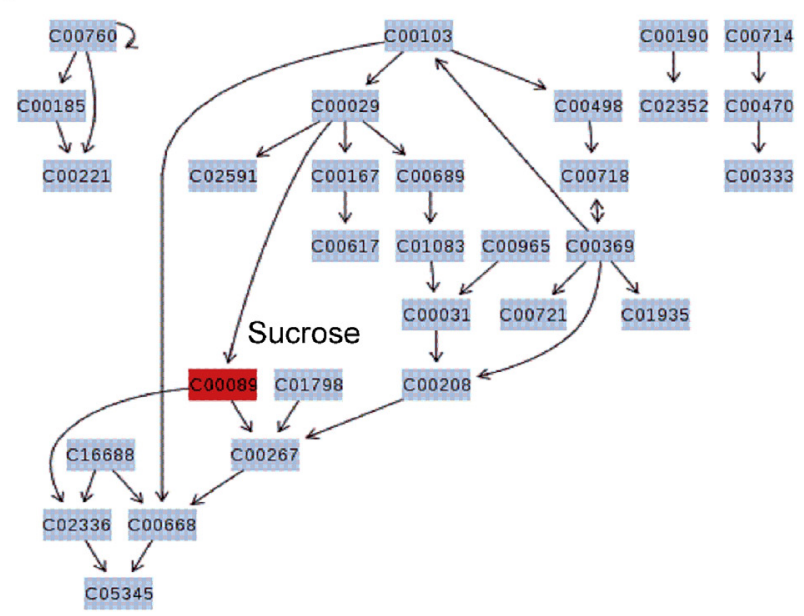

Fig. 3. Metabolic pathway analysis using MetaboAnalyst: (a) overview altered metabolic pathways; b) galactose metabolism pathway; c) starch and sucrose metabolism. The colour and size of each circle is based on the p value and the on value of pathways impact and the highlighted pathways were selected based on false discovery rate (FDR) less than 0.05 . (For interpretation of the references to color in this figure legend, the reader is referred to the Web version of this article.)

for each analytical method. For NMR dataset, unsupervised chemometric evaluation was performed by Principal Component Analysis (PCA) using The Unscrambler $\mathrm{X}^{\mathrm{TM}}$ program 10.4 (CAMO software, Woodbridge, NJ, USA). The area of non-deuterated water suppression ( $\delta 4.70$ to 4.90 - according to the saturation profile evaluation) was excluded. For LC-MS dataset, the chromatograms region between 0.5 and $8.0 \mathrm{~min}$ was used to perform PCA.

The alignment using COW (Correlation Optimized Warping) algorithm was applied over the NMR and LC-MS datasets. For HCA, the variables were mean-centered and Ward's method using Squared Euclidian distance was applied for distance metric. Singular Value Decomposition (SVD) algorithm was used for PCA, which were carried out after the baseline correction, normalization processing, and meancentered processing over the variables (composition).

In order to evaluate the variables that posses higher impact on the beans composition after controlled atmosphere, the classification model using Orthogonal Partial Least Squares Discriminant Analysis (OPLSDA) algorithm was applied using the PLS Toolbox ${ }^{\mathrm{TM}}$ program (version 8.6.2, Eigenvector Research Incorporated, Manson, WA, USA). It was performed pair comparison of control versus the treatments that leads to higher impact on the beans composition (as observed by PCA): control versus atmosphere with high humidity level (regardless the $\mathrm{CO}_{2}$ level); control versus atmosphere with low humidity level (regardless the $\mathrm{CO}_{2}$ level) at 6 months; control versus samples conditioned for 6 months (regardless the atmosphere condition); control versus samples conditioned for 6 months plus 7 days of shelf life (regardless the atmosphere condition). The loadings and coefficient plots were analyzed and the variables important for projection (VIP) with values higher than 1 were quantified and used as input for metabolic pathway analysis using MetaboAnalyst 4.0 (http://www.metaboanalyst.ca) (Chen et al., 2019; Liu et al., 2017, 2018; Xia, Psychogios, Young, \& Wishart, 2009). The organic compounds were quantified by an external reference method provided by the software $\mathrm{VnmJ}^{\mathrm{TM}}$ (version 4.2, Agilent) (Freitas et al., 2018; Lião et al., 2011).

\subsubsection{Univariate statistical analysis}

The color data results were submitted to analysis of variance using the software Origin ${ }^{\mathrm{TM}}$ 9.4. The variables with significant differences according to F-test $(p<0.05)$ were submitted to mean comparison by Tukey's test $(p<0.05)$.

\section{Results and discussion}

\subsection{Primary metabolites variability of the cotyledon by NMR}

The composition of the $P$. vulgaris cotyledon was evaluated after 6 months of storage: with low $\mathrm{CO}_{2}$ level and low humidity (LCLH); low $\mathrm{CO}_{2}$ level and high humidity (LCHH); high $\mathrm{CO}_{2}$ level and low humidity (HCLH); high $\mathrm{CO}_{2}$ level and high humidity $(\mathrm{HCHH})$; and after an additional 7 days storage under ambient condition. Fig. 1 presents a comparison among the ${ }^{1} \mathrm{H}$ NMR spectra from each experimental condition and control.

The spectra showed that the common bean comprised a high level of aliphatic, carbohydrates, and aromatic compounds (for complete 


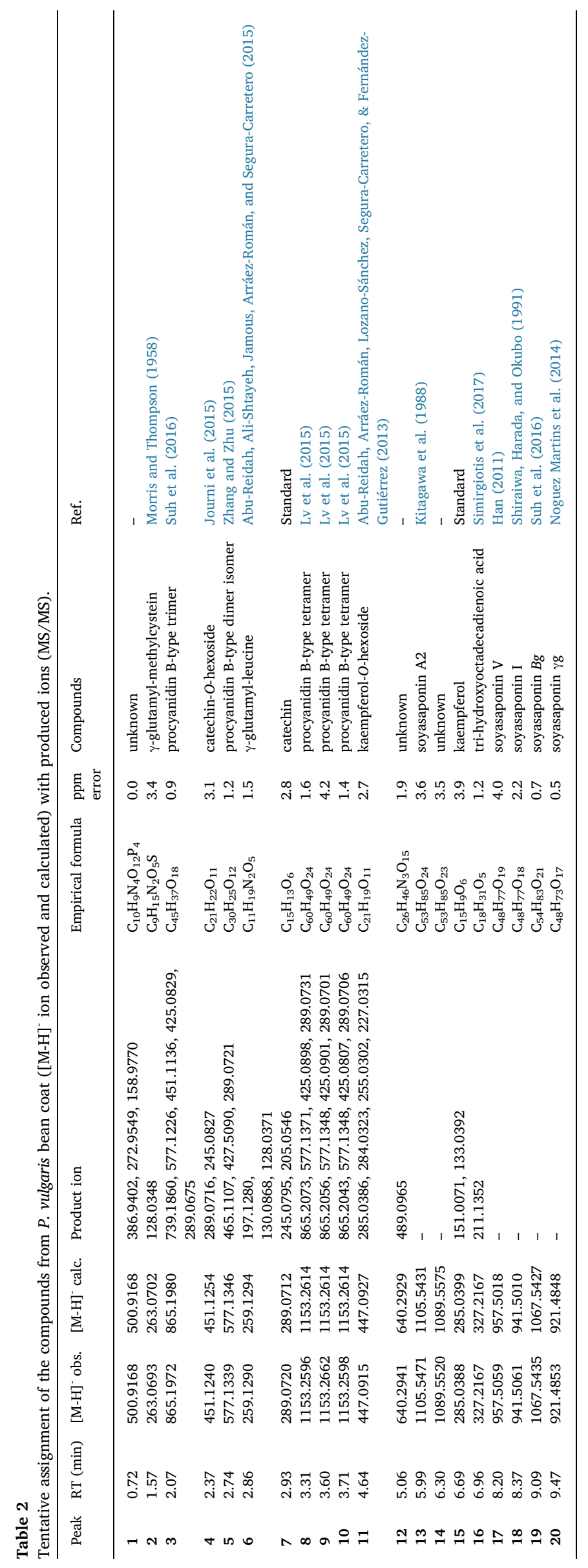

signaling see Supplementary Information). The major compounds detected were oligosaccharides (confirmed by cross-link of anomeric proton from glucose units with quaternary carbon of the fructose at $\delta$ 106.7 observed by HMBC) and sucrose. Therefore, in order to understand the variability of the primary metabolites in common beans according to different storage conditions, an unsupervised chemometric analysis by PCA was performed, which exhibited a separation tendency of the samples along PC1 $\times$ PC2 with $75.84 \%$ of the total variance explained (Fig. 2).

The scores plot presented the main tendency of separation of the common bean under different storage conditions according to the PC1 axis. The examination of the loadings showed the most important metabolites that lead their discrimination. In general, the principal information was the cotyledon metabolism recovery by the storage at ambient condition after the controlled atmosphere storage, from positive to negative values of PC1. In particular, beans stored under high humidity level and submitted to subsequent storage at ambient condition (HCHH.sl and LCHH.sl) are located close to control, showing their capacity to restore the metabolism. The common beans stored with low $\mathrm{CO}_{2}$ level and low humidity (LCLH and LCLH.sl) located at positive scores of both PC1 and PC2 axes, presenting the lower amount of the major compounds (negative PC2 loadings).

For comprehensive analysis of the metabolites, a supervised chemometric method by PLS with pair wise comparison (discriminant analysis of control versus the selected storage conditions) followed by the data orthogonalization was performed to assists the model interpretation (Izquierdo-García et al., 2011). The compounds with VIP scores higher than 1 were considered statistically significant for two classes discrimination. The analysis of those variables showed that regardless the used storage condition (atmosphere and time), the important metabolites were the same: raffinose $(\delta 5.42)$, sucrose $(\delta 5.42)$, stachyose $(\delta 5.46)$, verbascose $(\delta 5.46)$, acetylcholine $(\delta 3.21)$, citric acid $(\delta 2.58)$ and acetic acid $(\delta 1.92)$. This fact was in accordance with the PCA analysis, which showed the main variation with respect to PC1 axis. Therefore, the control samples versus 6 months of storage were used as model for metabolites analysis. In order to quantify the sucrose and oligosaccharides separately, some considerations were made. It was possible to obtain the value of sucrose and raffinose separately by considering the integration of the signal at $\delta 5.00$ (hydrogen of anomeric linkage between glucoses) of the oligosaccharides, which is 1 for raffinose, 2 for stachyose, and 3 for verbascose (Alves Filho et al., 2017; Lião et al., 2011). In addition, the signal at $\delta 5.46$ was considered solely from stachyose since the content of verbascose was nearly to zero in beans, especially in Pinto beans (Iyer, Salunkhe, Sathe, \& Rockland, 1980; Moghaddam et al., 2018).

To identify the relevant pathways linked to metabolites variation after the storage conditions, the variables were submitted to MetaboAnalyst (Xia et al., 2009; Xia \& Wishart, 2011). As shown in Fig. 3a, eight pathways were suggested to be associated with the metabolism response to storage conditions. However, pathways with false discovery rate $(\mathrm{P}<0.05)$ were considered as affected by the storage conditions, which includes galactose metabolism (Fig. 3b), and starch and sucrose metabolism (Fig. 3c). The metabolites in deep red color to yellow indicates an increased concentration of metabolites in stored beans and also higher impact on pathway and $-\log (\mathrm{P})$.

In non-photosynthetic tissues as beans, sucrose is the material for several metabolic pathways, providing energy and carbon skeletons for the production of amino acids, nucleotides and structural carbohydrates (Stein \& Granot, 2019). In addition, raffinose and stachyose are also all closely associated with plant energy metabolism (Eveland \& Jackson, 2011). In the galactose metabolism pathway, it was observed that the overexpression of certain saccharides as sucrose, raffinose, and stachyose were induced by storage conditions. As consequence to sucrose increasing, the starch and sucrose metabolism was also affected. Starch, sucrose, and galactose metabolisms participate in the germination and sprouting processes (Chen et al., 2019). In the light of these data, it 

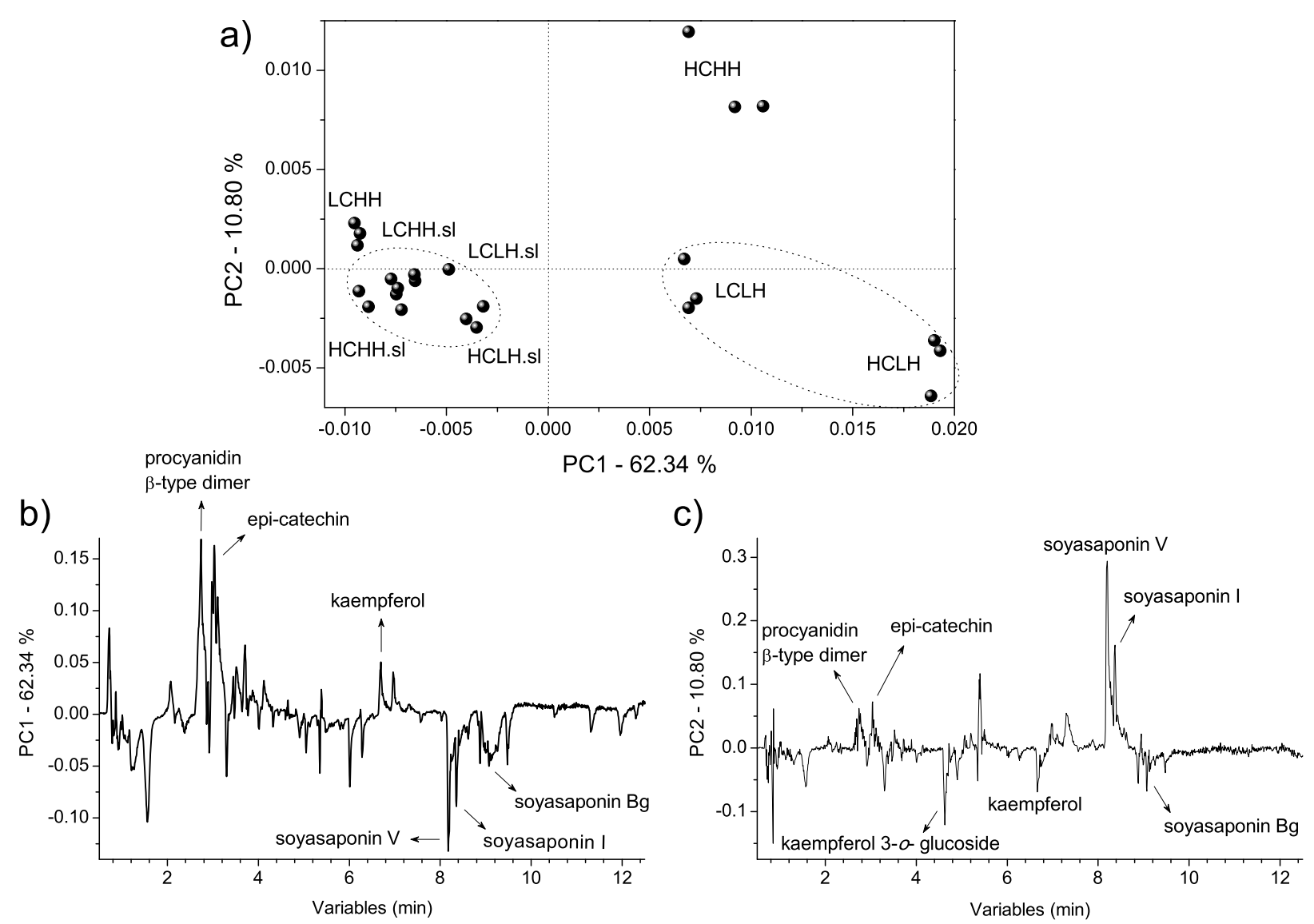

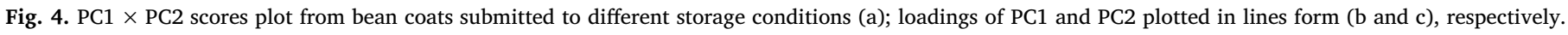

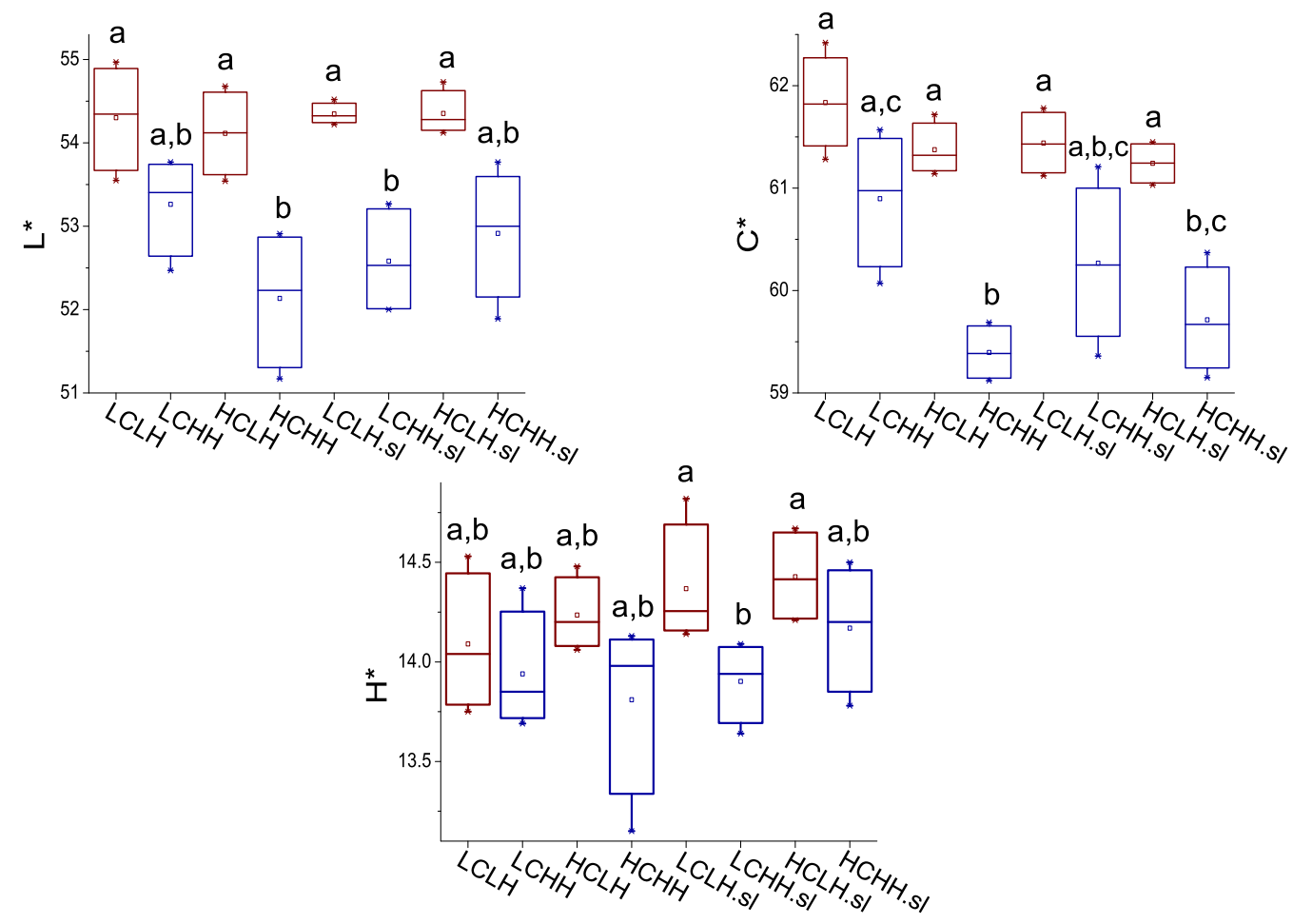

Fig. 5. Common beans coat color parameters of luminosity $\left(\mathrm{L}^{*}\right)$, chroma angle $\left(\mathrm{C}^{*}\right)$ and hue angle $\left(\mathrm{H}^{*}\right)$ presented as box-and-whiskers graphs. Legend: LCLH - low $\mathrm{CO}_{2}$ level, low humidity; LCHH - low $\mathrm{CO}_{2}$ level, high humidity; $\mathrm{HCLH}$ - high $\mathrm{CO}_{2}$ level; $\mathrm{HCHH}$ - high $\mathrm{CO}_{2}$ level, high humidity; sl - storage at ambient condition. (For interpretation of the references to color in this figure legend, the reader is referred to the Web version of this article.) 
seems possible that storage conditions induce the role in regulating the germination and sprouting processes. However, it was not observed changing on amino acids or lipid metabolism that are also related to the aforementioned mechanisms. Therefore, those mechanisms seem to be partially activated after 6 months regardless the atmosphere conditions. Despite this, the germination capability of the seeds after the storage time and conditions were not compromised as observed in the germination experiments (data not shown).

\subsection{Bean coat analysis}

It was characterized some of the major compounds according to their $m / z$ and fragmentation profiles (Table 2). A comparison among typical chromatographic profiles from bean coats are illustrated in Fig. 1SI.

The presence of procyanidin, catechin, kaempferol derivatives, and saponins was detected. The compounds 2 ( $\gamma$-glutamyl-methylcystein) and 6 ( $\gamma$-glutamyl-leucine) showed $[\mathrm{M}-\mathrm{H}]^{-}$ion at $\mathrm{m} / z 263.0693$ and 259.1290 , with fragments at $m / z 128$, and $197,130,128$, relatives to the loss of methylcysteine, glutamic acid, and leucine. The compound 4 showed a precursor ion at $m / z 451.1240$ and fragment product at $m / z$ 289.0716, which is compatible to the loss of hexose in catechin and, therefore, it was characterized as catechin-O-hexoside (Journi, Hammouda, Trabelsi-Ayadi, \& Chérif, 2015). The compounds 3, 5, 8-10 exhibited $[\mathrm{M}-\mathrm{H}]^{-}$at $m / z 577,865$, and 1153 , respectively. These compound and fragments were compatible with procyanidin $B$-type dimer, trimer, and tetramer isomers (Zhang \& Zhu, 2015). The compounds 7 and 15 exhibited precursor ion $[\mathrm{M}-\mathrm{H}]^{-}$at $\mathrm{m} / \mathrm{z} 289.0720$ and 285.0388, which correspond to catechin and kaempferol, respectively, by comparison with standard. In Phaseolus, kaempferol is commonly detected in $\mathrm{O}$-glycosidic form. The compound $\mathbf{1 1}$ showed a precursor ion $[\mathrm{M}-\mathrm{H}]^{-}$at $m / z 447.0915$ and fragment at $m / z 285.0386$, compatible with kaempferol product ion. Accordingly, it was identified as kaempferol-O-hexoside (Abu-Reidah, Arráez-Román, Lozano-Sánchez, SeguraCarretero, \& Fernández-Gutiérrez, 2013). The compounds 13, 17-20 exhibited molecular ion [M-H] ${ }^{-}$at $m / z$ 1105.5471, 957.5059, 941.5061, 1067.5435, and 921.4853, which were characterized as soyasaponin A2, V, I, Bg, and $\gamma$ g, respectively (Suh et al., 2016). The compound 16 with molecular ion [M-H] ${ }^{-}$at $m / z 327.2167$ was tentatively assigned as tri-hydroxyoctadecadienoic acid based on the fragmentation pattern (Simirgiotis et al., 2017). The compounds 1, 12 and 14 were not identified.

The aforementioned compounds were detected in all samples in different intensities. Therefore, due to the elevate complexity of the data chemometric analysis was developed. Fig. 4 shows the PC1 $\times$ PC2 scores plot, discriminating samples regarding different storage conditions with $73 \%$ of the total variance explained. Fig. $4 \mathrm{~b}$ and $\mathrm{c}$ show the corresponding loadings graph for both PC1 and PC2 axes, respectively.

Common bean stored under low humidity was located at positive scores of PC1 and negative of PC2 and furthermore, those beans stored under high $\mathrm{CO}_{2}$ condition were located at higher positive scores of PC1 and PC2 concomitantly. This fact was related to appropriated storage, since low $\mathrm{O}_{2}$ and high $\mathrm{CO}_{2}$ atmosphere with reduced humidity lead to arthropods death during grain storage, preserving the bean quality (Freitas et al., 2016). At negative scores of PC1 are located the beans submitted to additional 7 days of storage at ambient condition, and the beans stored under high humidity with low $\mathrm{CO}_{2}$ level (closest to storage at ambient condition), which indicate the reactivation of the metabolism after withdrawal of the beans from the controlled atmosphere.

According to loadings graph from PC1 (Fig. 4b), it was noticeable the reduction of procyanidin $B$-type dimer, epi-catechin, and kaempferol in beans submitted to 7 days of storage at ambient condition, as well as beans stored at low $\mathrm{CO}_{2}$ and high relative humidity. In general, pigments responsible for bean coat color are flavonoids (Ranilla, Genovese, \& Lajolo, 2007). The proanthocyanidins are oligomeric flavonoids originated from the condensation of catechin, epicatechin, and gallic acid esters. This class of compounds oxidizes to reactive quinones that interact with proteins, resulting in the darkening of the bean coat (Coutin et al., 2017). Therefore, the decrease of procyanidin $B$-type dimer, kaempferol; and epi-catechin can be associated to bean coat darkening after 7 days of storage at ambient condition as corroborate by color evaluation (Fig. 5). In addition, it also indicated that the beans submitted to low $\mathrm{CO}_{2}$ and high relative humidity might present coat darkening. Often, kaempferol content reduces after darkening (Beninger et al., 2005).

For beans located in negative scores of PC1, an increase in content of the saponins soyasaponin $B g$, soyasaponin $I$, soyasaponin $V$ was observed. The soyasaponins are triterpenoid aglycones, and commonly found in P. vulgaris (Kitagawa et al., 1988). Therefore, higher content of saponins after 7 days of storage at ambient condition may indicate the restoration of the bean metabolism. This dynamics is more noticeable by observing the loadings graph of PC2 axis (Fig. 4c), in which beans submitted to high $\mathrm{CO}_{2}$ and high relative humidity presented high amounts of the saponins. It is known that bean coat chemical pattern and color in $P$. vulgaris is controlled by a group of genes, which regulate the flavonol and anthocyanin biosynthetic pathways (McClean, Lee, Otto, Gepts, \& Bassett, 2002). Therefore, alterations in storage conditions affected the biosynthesis of these compounds.

\subsection{Bean color}

Since the color of common bean is an important visual attribute and presents important influence on consumer's intention-to-buy and acceptability, the coat color was evaluated in order to correlate to storage conditions (Fig. 5). The common bean storage under low humidity (40\%) showed highest luminosities, which indicate the preservation of the lighter color. However, the color was not influenced by different $\mathrm{CO}_{2}$ levels or 7 days of storage condition after controlled atmosphere storage because no significant differences were observed $(95 \%$ of reliability). It is known that common bean stored under high temperature and/or humidity are susceptible to development of hardening and darkening phenomena (Coelho, Prudencio, Christ, Sampaio, \& Schoeninger, 2013). Therefore, beans stored in lower humidity presented higher L* (luminosity) and $C^{*}$ (chroma) values, as well as increases in amounts of proanthocyanidin $B$-type dimer, epi-catechin, and kaempferol contents (Fig. 4b). The low procyanidin $B$-type dimer content was coherent with darkening of the bean coat due to proanthocyanidin oxidation to reactive quinones (Ranilla et al., 2007). Hue angles $\left(\mathrm{H}^{*}\right)$ from stored beans were similar and ranged within the $90^{\circ}$ region, suggesting an apparent reddish yellow color.

\section{Conclusion}

The NMR spectroscopy coupled to chemometrics enables the study of effected pathway of the beans submitted to controlled atmosphere. It was observed changing on galactose, starch and sucrose pathways that are closely associated to regulation on the germination and sprouting processes. However, it was not observed changing on amino acids or lipid metabolism, and metabolites also linked to aforementioned mechanisms, indicating that those mechanisms seems to be partially activated after 6 months regardless the atmosphere conditions. For LC-MS analysis, it was observed that common beans stored under low relative humidity presented highest luminosity and chroma values, which was corroborated by the reduction of proanthocyanidin $B$-type dimer, epicatechin, and kaempferol contents indicating correlations between color and chemical parameters. These findings showed bean coat darkening when submitted to high humidity during the controlled atmosphere storage. Through the LC-MS analysis, it was also observed higher content of saponins after 7 days of storage at ambient condition, as well as in the beans stored at low $\mathrm{CO}_{2}$ and high relative humidity, indicating the restoration of bean metabolism. In general, seeds presented viability for germination after storage time regardless the atmosphere condition, 
despite of the darkening process observed.

\section{Declaration of competing interest}

The authors declare that there is no conflict of interest.

\section{Acknowledgments}

The authors acknowledge financial support from EMBRAPA (02.11.07.010), CNPq (scholarship 314737/2018-9) and FUNCAP (DCR-0024-01686.01.00/15).

\section{Appendix A. Supplementary data}

Supplementary data to this article can be found online at https:// doi.org/10.1016/j.lwt.2019.108673.

\section{References}

Abu-Reidah, I. M., Ali-Shtayeh, M. S., Jamous, R. M., Arráez-Román, D., \& SeguraCarretero, A. (2015). HPLC-DAD-ESI-MS/MS screening of bioactive components from Rhus coriaria L. (Sumac) fruits. Food Chemistry, 166, 179-191. https://doi.org/ 10.1016/j.foodchem.2014.06.011.

Abu-Reidah, I. M., Arráez-Román, D., Lozano-Sánchez, J., Segura-Carretero, A., \& Fernández-Gutiérrez, A. (2013). Phytochemical characterisation of green beans (Phaseolus vulgaris L.) by using high-performance liquid chromatography coupled with time-of-flight mass spectrometry. Phytochemical Analysis, 24(2), 105-116. https://doi.org/10.1002/pca.2385.

Alves Filho, E. G., Silva, L. M., Teofilo, E. M., Larsen, F. H., \& de Brito, E. S. (2017). Genotype evaluation of cowpea seeds (Vigna unguiculata) using 1H qNMR combined with exploratory tools and solid-state NMR. Food Research International, 91, 140-147. https://doi.org/10.1016/j.foodres.2016.12.007.

Beninger, C. W., Gu, L., Prior, R. L., Junk, D. C., Vandenberg, A., \& Bett, K. E. (2005). Changes in polyphenols of the seed coat during the after-darkening process in pinto beans (Phaseolus vulgaris L.). Journal of Agricultural and Food Chemistry, 53(20), 7777-7782. https://doi.org/10.1021/jf0500511.

Chen, L., Wu, J.e., Li, Z., Liu, Q., Zhao, X., \& Yang, H. (2019). Metabolomic analysis of energy regulated germination and sprouting of organic mung bean (Vigna radiata) using NMR spectroscopy. Food Chemistry, 286, 87-97. https://doi.org/10.1016/j. foodchem. 2019.01.183.

Choze, R., Alcantara, G. B., Alves Filho, E.d. G., e Silva, L. M. A., Faria, J. C., \& Lião, L. M. (2013). Distinction between a transgenic and a conventional common bean genotype by 1 H HR-MAS NMR. Food Chemistry, 141(3), 2841-2847. https://doi.org/10.1016/j. foodchem.2013.05.123.

Coelho, S. R., Prudencio, S. H., Christ, D., Sampaio, S. C., \& Schoeninger, V. (2013). Physico-chemical properties of common beans under natural and accelerated storage conditions. Ciencia e Investigacian Agraria, 40(3), 629-636. https://doi.org/10.4067/ S0718-16202013000300015.

Coutin, J. A. F., Munholland, S., Silva, A., Subedi, S., Lukens, L., Crosby, W. L., ... Bozzo, G. G. (2017). Proanthocyanidin accumulation and transcriptional responses in the seed coat of cranberry beans (Phaseolus vulgaris L.) with different susceptibility to postharvest darkening. BMC Plant Biology, 17(1), 89. https://doi.org/10.1186/ s12870-017-1037-z.

Delouche, J. C., \& Baskin, C. C. (2016). Accelerated aging techniques for predicting the relative storability of seed lots. Seed Science \& Technology, 1, 427-452.

Eveland, A. L., \& Jackson, D. P. (2011). Sugars, signalling, and plant development. Journal of Experimental Botany, 63(9), 3367-3377. https://doi.org/10.1093/jxb/err379.

Freitas, J., Alves Filho, E. G., Silva, L. M. A., Zocolo, G. J., de Brito, E. S., \& Gramosa, N. V. (2018). Chemometric analysis of NMR and GC datasets for chemotype characterization of essential oils from different species of Ocimum. Talanta, 180, 329-336. https://doi.org/10.1016/j.talanta.2017.12.053.

Freitas, R., Faroni, L., \& Sousa, A. (2016). Hermetic storage for control of common bean weevil, Acanthoscelides obtectus (Say). Journal of Stored Products Research, 66, 1-5. https://doi.org/10.1016/j.jspr.2015.12.004.

Geigenberger, P. (2003). Response of plant metabolism to too little oxygen. Current Opinion in Plant Biology, 6(3), 247-256. https://doi.org/10.1016/S1369-5266(03) 00038-4.

Giusti, F., Caprioli, G., Ricciutelli, M., Vittori, S., \& Sagratini, G. (2017). Determination of fourteen polyphenols in pulses by high performance liquid chromatography-diode array detection (HPLC-DAD) and correlation study with antioxidant activity and colour. Food Chemistry, 221, 689-697. https://doi.org/10.1016/j.foodchem.2016.11. 118.

Han, S.-J. (2011). HPLC/MS/MS method for determination of soyasaponins in the soybean varieties. Korean Journal of Crop Science, 56(3), 244-249. https://doi.org/10. $7740 /$ kjcs.2011.56.3.244.

Iyer, V., Salunkhe, D. K., Sathe, S. K., \& Rockland, L. B. (1980). Quick-cooking beans (Phaseolus vulgaris L.): II. Phytates, oligosaccharides, and antienzymes. Plant Foods for Human Nutrition, 30(1), 45-52. https://doi.org/10.1007/bf01112103.

Izquierdo-García, J. L., Villa, P., Kyriazis, A., del Puerto-Nevado, L., Pérez-Rial, S., Rodriguez, I., ... Ruiz-Cabello, J. (2011). Descriptive review of current NMR-based metabolomic data analysis packages. Progress in Nuclear Magnetic Resonance
Spectroscopy, 59(3), 263-270. https://doi.org/10.1016/j.pnmrs.2011.02.001.

Journi, M., Hammouda, H., Trabelsi-Ayadi, M., \& Chérif, J. K. (2015). Quantitative determination and identification of phenolic compounds of three Tunisian legumes: Vicia faba, Lens culinaris and Phaseolus vulgaris. Advances in Chemistry and Biochemistry Sciences, 2(3), 01-12.

Kitagawa, I., Taniyama, T., Nagahama, Y., Okubo, K., Yamauchi, F., \& Yoshikawa, M. (1988). Saponin and sapogenol. XLII.: Structures of acetyl-soyasaponins A1, A2, and A3, astringent partially acetylated bisdesmosides of soyasapogenol A, from American soybean, the seeds of Glycine max MERRILL. Chemical and Pharmaceutical Bulletin, 36(8), 2819-2828. https://doi.org/10.1248/cpb.36.2819.

Lião, L., Alves Filho, E., Silva, L., Choze, R., Alcantara, G., \& Bassinello, P. (2011). Quantification of oligosaccharides from common beans by HR-MAS NMR. Magnetic Resonance in Food Science, 47-53.

Liu, K., McWatters, K. H., \& Phillips, R. D. (1992). Protein insolubilization and thermal destabilization during storage as related to hard-to-cook defect in cowpeas. Journal of Agricultural and Food Chemistry, 40(12), 2483-2487. https://doi.org/10.1021/ jf00024a028.

Liu, Q., Wu, J.e., Lim, Z. Y., Aggarwal, A., Yang, H., \& Wang, S. (2017). Evaluation of the metabolic response of Escherichia coli to electrolysed water by 1H NMR spectroscopy. Lebensmittel-Wissenschaft und -Technologie- Food Science and Technology, 79, 428-436. https://doi.org/10.1016/j.lwt.2017.01.066.

Liu, Q., Wu, J.e., Lim, Z. Y., Lai, S., Lee, N., \& Yang, H. (2018). Metabolite profiling of Listeria innocua for unravelling the inactivation mechanism of electrolysed water by nuclear magnetic resonance spectroscopy. International Journal of Food Microbiology, 271, 24-32. https://doi.org/10.1016/j.ijfoodmicro.2018.02.014.

Lv, Q., Luo, F., Zhao, X., Liu, Y., Hu, G., Sun, C., Li, X., \& Chen, K. (2015). Identification of proanthocyanidins from Litchi (Litchi chinensis Sonn.) pulp by LC-ESI-Q-TOF-MS and their antioxidant activity. PloS one, 10(3), e0120480. https://doi.org/10.1371/ journal.pone. 0120480 .

McClean, P., Lee, R., Otto, C., Gepts, P., \& Bassett, M. (2002). Molecular and phenotypic mapping of genes controlling seed coat pattern and color in common bean (Phaseolus vulgaris L.). Journal of Heredity, 93(2), 148-152. https://doi.org/10.1093/jhered/93. 2.148 .

Moghaddam, S. M., Brick, M. A., Echeverria, D., Thompson, H. J., Brick, L. A., Lee, R., .. McClean, P. E. (2018). Genetic architecture of dietary fiber and oligosaccharide content in a middle American panel of edible dry bean. The Plant Genome, 11(1) https://doi.org/10.3835/plantgenome2017.08.0074.

Morris, C., \& Thompson, J. (1958). The detection, isolation, and identification of gammaglutamyl-S-methylcysteine from beans. Archives of Biochemistry and Biophysics, 73(1), 281. https://doi.org/10.1016/0003-9861(58)90266-2.

Noguez Martins, A. B., Marini, P., de Magalhães Bandeira, J., Gouvêa de Borba, I. C., Rodrigues Quineper, R., Munt de Moraes, D., \& Amaral Villela, F. (2014). Vigor: separação de lotes de sementes pela atividade respiratória. Interciencia, 39(4) 03781844/14/04/260-06.

Pirhayati, M., Soltanizadeh, N., \& Kadivar, M. (2011). Chemical and microstructural evaluation of 'hard-to-cook'phenomenon in legumes (pinto bean and small-type lentil). International Journal of Food Science and Technology, 46(9), 1884-1890. https://doi.org/10.1111/j.1365-2621.2011.02697.x.

Prolla, I. R. D., Barbosa, R. G., Veeck, A. P. L., Augusti, P. R., Silva, L. P.d., Ribeiro, N. D., et al. (2010). Cultivar, harvest year, and storage conditions affecting nutritional quality of common beans (Phaseolus vulgaris L). Food Science and Technology, 30, 96-102. https://doi.org/10.1590/S0101-20612010000500016.

Ranilla, L. G., Genovese, M. I., \& Lajolo, F. M. (2007). Polyphenols and antioxidant capacity of seed coat and cotyledon from Brazilian and Peruvian bean cultivars (Phaseolus vulgaris L.). Journal of Agricultural and Food Chemistry, 55(1), 90-98. https://doi.org/10.1021/jf062785j.

Shiraiwa, M., Harada, K., \& Okubo, K. (1991). Composition and structure of "group B saponin" in soybean seed. Agricultural and Biological Chemistry, 55(4), 911-917. https://doi.org/10.1080/00021369.1991.10870686.

Simirgiotis, M. J., Quispe, C., Mocan, A., Villatoro, J. M., Areche, C., Bórquez, J., .. Echiburu-Chau, C. (2017). UHPLC high resolution orbitrap metabolomic fingerprinting of the unique species Ophryosporus triangularis Meyen from the Atacama Desert, Northern Chile. Revista Brasileira de Farmacognosia, 27(2), 179-187. https:// doi.org/10.1016/j.bjp.2016.10.002.

de Souza Aguiar, R. W., Brito, D. R., de Mendonça Lopes, M., Silva, R. R., Fidelis, R. R., de Sousa, C. M., et al. (2015). Effect of carbon dioxide on quality of rice seeds. Bioscience Journal, 31(5)https://doi.org/10.14393/BJ-v31n5a2015-26525.

Stein, O., \& Granot, D. (2019). An overview of sucrose synthases in plants. Frontiers of Plant Science, 10. 95-95 https://doi.org/10.3389/fpls.2019.00095.

Suh, D. H., Jung, E. S., Park, H. M., Kim, S. H., Lee, S., Jo, Y. H., ... Lee, C. H. (2016). Comparison of metabolites variation and antiobesity effects of fermented versus nonfermented mixtures of Cudrania tricuspidata, Lonicera caerulea, and soybean according to fermentation in vitro and in vivo. PLoS One, 11(2), e0149022. https://doi. org/10.1371/journal.pone.0149022.

Vanier, N. L., Rupollo, G., Paraginski, R. T., de Oliveira, M., \& Elias, M. C. (2014). Effects of nitrogen-modified atmosphere storage on physical, chemical and technological properties of Carioca bean. Current Agricultural Science and Technology, 20(1)https:// doi.org/10.18539/CAST.V20I1.2984.

Xia, J., Psychogios, N., Young, N., \& Wishart, D. S. (2009). MetaboAnalyst: A web server for metabolomic data analysis and interpretation. Nucleic Acids Research, 37, W652-W660. (Web Server issue) https://doi.org/10.1093/nar/gkp356.

Xia, J., \& Wishart, D. S. (2011). Web-based inference of biological patterns, functions and pathways from metabolomic data using MetaboAnalyst. Nature Protocols, 6, 743. https://doi.org/10.1038/nprot.2011.319.

Zhang, S., \& Zhu, M. (2015). Characterization of polyphenolics in grape pomace extracts using ESI Q-TOF MS/MS. Journal of Food Science and Nutrition, 1(01), 1-10. https:// doi.org/10.24966/FSN-1076/100001. 